\section{Clinical outcomes after Ahmed valve implantation in refractory paediatric glaucoma}

\author{
Abstract \\ Purpose To evaluate clinical outcomes after \\ Ahmed valve implantation in refractory \\ paediatric glaucoma. \\ Methods A retrospective review was \\ conducted on 34 eyes from 29 patients with \\ refractory glaucoma, who were younger than \\ 18 years of age and who underwent Ahmed \\ valve implantation. The main outcome \\ measures were intraocular pressures (IOPs) \\ and the number of glaucoma medications \\ used. Qualified success was defined as IOP \\ $\leqslant 21 \mathrm{~mm} \mathrm{Hg}$ regardless of the number of \\ glaucoma medications. Complete success was \\ defined as IOP $\leqslant 21 \mathrm{~mm} \mathrm{Hg}$ without glaucoma \\ medication. \\ Results Mean age at operation was \\ 5.5 years (range, $0-16)$. Fifteen eyes $(44.1 \%)$ \\ had undergone previous glaucoma surgery \\ before Ahmed valve implantation. Mean \\ follow-up time was 29.1 months (range, 3-31). \\ IOP was reduced from a preoperative \\ mean of $37.5 \pm 7.3$ to $18.4 \pm 7.3 \mathrm{~mm} \mathrm{Hg}$ at \\ 6 months postoperatively $(P<0.01)$. \\ At 12 months after surgery, the success \\ rates were $63.3 \%$ (qualified success) and \\ $13.3 \%$ (complete success). The cumulative \\ probabilities of qualified success at 6, 12, \\ and 24 months after Ahmed valve \\ implantation were $89.0,68.6$, and $45.7 \%$, \\ respectively. The median time of survival \\ was $19.6 \pm 0.9$ months. \\ Conclusions Ahmed valve implantation is \\ effective in lowering IOP in refractory \\ paediatric glaucoma, with limited survival \\ after long-term follow-up. Addition of a \\ second Ahmed valve may be effective in the \\ management of failure after primary \\ implantation. \\ Eye (2009) 23, 1427-1435; doi:10.1038/eye.2008.261; \\ published online 29 August 2008
}

HK Yang ${ }^{1,2}$ and $\mathrm{KH}$ Park $^{1,2}$

Keywords: Ahmed valve implantation;

glaucoma drainage device; intraocular pressure; paediatric glaucoma

\section{Introduction}

In paediatric glaucoma, the mainstay of treatment is surgical management, ${ }^{1,2}$ whereas medical management is used adjunctively to reduce intraocular pressures (IOPs). ${ }^{3-7}$ Goniotomy and trabeculotomy were initially considered for congenital glaucoma, with comparable results. ${ }^{8-11}$ Viscotrabeculotomy, using viscoelastic material during trabeculotomy, may increase success rates through prevention of both postoperative haemorrhage and adhesion of the incision lips. ${ }^{12,13}$ Trabeculectomy also shows

encouraging results, and may be supplemented by mitomycin $\mathrm{C}$ or combined with trabeculotomy. ${ }^{14-18}$ However, overall success rates after paediatric glaucoma surgery range from 60 to $92 \%$, with the rates declining over time. Furthermore, some paediatric glaucoma respond poorly to goniotomy or trabeculectomy. ${ }^{8,19}$ Cycloablative therapy can be considered in refractory cases, but success rates are limited with a higher risk of complications. $^{20-22}$

Glaucoma drainage devices are widely used in the treatment of refractory paediatric glaucoma, especially when filtering surgery has failed or is known to have a high risk of failure, such as significant conjunctival scarring. ${ }^{23,24}$ The first glaucoma drainage device used in the paediatric population was the Molteno implant (IOP Inc., Costa Mesa, CA, USA), ${ }^{25}$ followed by the Baerveldt implant (Pharmacia and Upjohn Inc., Kalamazoo, MI, USA) ${ }^{23,26,27}$ and Ahmed valve implant (New World Medical Inc., Rancho Cucamonga, CA, USA). ${ }^{23}$ The Ahmed valve
${ }^{1}$ Department of Ophthalmology, Seoul National University College of Medicine, Seoul, Korea

${ }^{2}$ Artificial Eye Center of Clinical Research Institute, Seoul National University Hospital, Seoul, Korea

Correspondence: KH Park, Department of Ophthalmology, Seoul National University College of Medicine, 28 Yongon-dong, Chongno-gu, Seoul 110-744 Korea

Tel: + 8222072 2438; Fax: + 8227413187 . E-mail: kihopark@ snu.ac.kr

Received: 7 March 2008 Accepted in revised form: 19 July 2008 Published online: 29 August 2008 
implant has a protective sleeve, which is designed to open when the aqueous pressure is higher than $8 \mathrm{~mm} \mathrm{Hg}$. This is highly effective in reducing the risk of early postoperative hypotony compared to the Molteno and Baerveldt implants, which do not have sleeves. Several reports of Ahmed valve implantation (AVI) used in refractory paediatric glaucoma show comparable results to AVI in adults and implantation of other drainage devices. ${ }^{28-34}$ This study was conducted to evaluate the efficacy, complications, and risk factors for failure after AVI in paediatric glaucoma patients who were refractory to medical treatment or other surgical procedures.

\section{Materials and methods}

We retrospectively reviewed the medical charts of patients younger than 18-year-old, who had uncontrolled IOP despite medical therapy or previous glaucoma surgeries, and who underwent AVI performed by a single glaucoma surgeon (KHP) between July 2002 and July 2007 at Seoul National University Children's Hospital. The minimum required follow-up period after surgery was 6 months. The study was conducted under Institutional Review Board (IRB) approval.

The preoperative clinical data obtained for each patient included the patient's age at diagnosis, age at the time of surgery, gender, specific type of glaucoma diagnosis, history of other ocular or systemic disease, ocular trauma or surgery, anterior segment findings, posterior segment findings, IOP, number of glaucoma medications, and visual fields, if possible. All IOPs were measured by Tono-pen (Mentor, Norwell, MA, USA), Goldmann applanation tonometer, or Perkins applanation tonometer.

Patients were examined postoperatively at 1 day, 1 week, 1 month, 3 months, and 6 months, then every 3 months depending on the patient's clinical status. The IOP and number of glaucoma medications were noted at all examinations. Follow-up visits also included slit-lamp examination for evaluation of corneal clarity, tube position and patency, anterior segment inflammation, lens status, tube and scleral patch coverage, and bleb appearance. Quantitative visual acuity measurements were obtained whenever possible, and dilated indirect and direct ophthalmoscopy was performed periodically, with notation of any vitreoretinal pathology.

Ahmed valves designed for children (model S-3) were used for patients 12 -year-old or under $(n=31)$. The standard-sized plates (model S-2) were used for patients older than 12-year-old ( $n=3 ; 8.7 \%$ ). Model S-3 is smaller than the standard S-2. Although the tube length $(25.0 \mathrm{~mm})$ and internal, external diameters $(0.305$, $0.635 \mathrm{~mm})$ are equivalent, the valve width $(9.6 \mathrm{~mm}$; S-3 vs $13.0 \mathrm{~mm}$; S-2) and length (10.0 vs $16.0 \mathrm{~mm})$ are shorter in the paediatric model, and the surface area is half the size of the adult model (96.0 vs $184.0 \mathrm{~mm}^{2}$ ).

The surgical procedure for AVI is as follows: a fornix-based conjunctival incision was created in the superior temporal quadrant or superior nasal area (in cases in which the temporal quadrant was previously operated). After the sclera was exposed, a partial thickness limbal-based scleral flap was cut in a rectangular shape. The tube was primed using balanced salt solution, and the Ahmed drainage plate was tucked under the subconjunctival space and sutured to the underlying sclera with its anterior edge $6-8 \mathrm{~mm}$ posterior to the limbus, using two 8-0 nylon anchoring sutures.

To decrease the risk of early postoperative hypotony, partial ligation of the tube was accomplished by the method described by Dr Kee, using 6-0 polypropylene (Prolene; Ethicon Ltd., UK) as a stent by locating it beside the tube, ligating both the tube and the stent with 8-0 polyglactin (Vicryl; Ethicon Ltd.), and then withdrawing the stent. ${ }^{35}$ The tube was trimmed bevel up so that it reached the mid-iris. A 23-gauge needle was used to enter the anterior chamber at the surgical limbus under the scleral flap, aiming toward the centre of the pupil. The tube was inserted through this opening, and no additional suture was made to secure the tube to the sclera. The partial thickness scleral flap covered the tube and was sutured to the sclera posteriorly using 8-0 polyglactin (Vicryl; Ethicon Ltd.). The conjunctiva was sutured using 8-0 polyglactin (Vicryl; Ethicon Ltd.) at the anterior edge of the conjunctival flap, so that the scleral patch was completely covered. A subconjunctival injection of dexamethasone was given. Postoperatively, topical antibiotics, steroid drops (usually in a combination), and atropine were prescribed, all of which were slowly tapered over the course of 4-8 weeks.

The primary outcome measures were IOP and the number of glaucoma medications used at each period. Qualified success was defined as IOP $\leqslant 21 \mathrm{~mm} \mathrm{Hg}$ regardless of the number of glaucoma medications. Complete success was defined as IOP $\leqslant 21 \mathrm{~mm} \mathrm{Hg}$ without glaucoma medication. Cases with visually significant complications were considered failures. Success rates after AVI was evaluated at each follow-up period.

Statistical analyses were performed using SPSS for Windows (version 15.0, Statistical Package for the Social Sciences, SPSS Inc., Chicago, IL, USA). Postoperative IOP and number of glaucoma medications were compared with preoperative values using the paired Student's $t$-test and Wilcoxon signed rank test. Univariate analysis of risk factors for failure in different subgroups was made using Pearson's $\chi^{2}$-test or Fisher's exact test. The cumulative probability of success was examined by Kaplan-Meier 
life table. A $P$-value of $<0.05$ was considered statistically significant.

\section{Results}

The clinical characteristics of the patients are summarized in Table 1. A total of 34 eyes of 29 patients were enrolled in this study. Mean age at operation was $5.5 \pm 4.2$ (range, $0-16$ ) years and mean follow-up period was $29.1 \pm 16.2$ (range, 6-63) months. Five (17.2\%) patients underwent bilateral AVI. The indications for AVI are shown in Table 1.

In total, 15 eyes (44.1\%) had undergone previous glaucoma surgery prior to AVI, including trabeculotomy

Table 1 Patients' demographic data

\begin{tabular}{|c|c|}
\hline Total patients & 29 \\
\hline Total eyes & 34 \\
\hline \multicolumn{2}{|l|}{ Gender } \\
\hline Male & $18(62.1 \%)$ \\
\hline Female & $11(37.9 \%)$ \\
\hline \multicolumn{2}{|l|}{ Bilaterality of glaucoma } \\
\hline Bilateral & $16(55.2 \%)$ \\
\hline Unilateral & $13(44.8 \%)$ \\
\hline Age at diagnosis (years) & $2.9 \pm 4.2(0-16)$ \\
\hline Age at operation (years) & $5.5 \pm 4.2(0-16)$ \\
\hline Follow-up period (months) & $29.1 \pm 16.2(6-63)$ \\
\hline \multicolumn{2}{|l|}{ Bilaterality of Ahmed implant } \\
\hline Bilateral & $5(17.2 \%)$ \\
\hline Unilateral & $24(82.8 \%)$ \\
\hline \multicolumn{2}{|l|}{ Diagnosis } \\
\hline Congenital glaucoma & $12(35.3 \%)$ \\
\hline $\begin{array}{l}\text { Glaucoma following lensectomy } \\
\text { for congenital cataracts }\end{array}$ & $11(32.4 \%)$ \\
\hline Aphakic glaucoma & $5(14.7 \%)$ \\
\hline Pseudophakic glaucoma & $6(17.6 \%)$ \\
\hline $\begin{array}{l}\text { Developmental glaucoma with } \\
\text { associated ocular anomalies }\end{array}$ & $5(14.7 \%)$ \\
\hline Aniridia & $1(2.9 \%)$ \\
\hline $\begin{array}{l}\text { Microphathalmia } \\
\text { (complex) }\end{array}$ & $1(2.9 \%)$ \\
\hline Axenfeld-Rieger anomaly & $3(8.8 \%)$ \\
\hline Neovascular Glaucoma & $4(1.0 \%)$ \\
\hline $\begin{array}{l}\text { Developmental glaucoma } \\
\text { with associated systemic } \\
\text { disease }^{\text {a }}\end{array}$ & $1(2.9 \%)$ \\
\hline $\begin{array}{l}\text { Glaucoma associated with } \\
\text { cicatricial } \mathrm{ROP}^{\mathrm{b}}\end{array}$ & $1(2.9 \%)$ \\
\hline
\end{tabular}

Abbreviation: ROP, retinopathy of prematurity. aDown syndrome with unilateral congenital glaucoma.

${ }^{\mathrm{b}}$ Cicatricial ROP with secondary angle closure. in 11 eyes (32.4\%), trabeculectomy with antimetabolites in 13 eyes $(38.2 \%)$, cyclophotocoagulation in 4 eyes $(11.8 \%)$, and previous implant (Molteno) in 1 eye (2.9\%). The mean number of prior glaucoma surgeries performed on each eye was $1.1 \pm 1.4$ (range, $0-4$ ). The number of eyes that underwent previous glaucoma surgeries was distributed as follows: one surgery $(n=2$; $5.9 \%)$, two surgeries $(n=6 ; 17.7 \%)$, three surgeries $(n=4$; $11.8 \%)$, four surgeries $(n=3 ; 8.8 \%)$. The diagnosis of the 15 eyes that underwent secondary AVI were: congenital glaucoma $(n=10)$, aphakic glaucoma $(n=1$; who had undergone filtering surgeries in another institution), anterior segment dysgenesis (mild forms of AxenfeldRieger anomaly or aniridia; $n=3$ ), and Down syndrome $(n=1)$.

The indications of the 19 patients $(55.9 \%)$ that underwent primary AVI without any previous glaucoma surgery were: glaucoma following congenital cataract surgery (pseudophakic or aphakic glaucoma; $n=10$ ), neovascular glaucoma $(n=4)$, severe anterior segment dysgenesis (Axenfeld-Rieger anomaly, complex microphthalmia $n=2$ ), congenital glaucoma with corneal opacity $(n=2)$, and cicatricial retinopathy of prematurity (ROP) with corneal opacity $(n=1)$.

Two eyes (5.8\%) underwent combined procedures at the time of AVI. One was penetrating keratoplasty (PKP) in congenital glaucoma with total corneal opacity, and the other was anterior segment reconstruction consisting of lensectomy and pupilloplasty in complex microphthalmia.

Intraocular pressure was reduced from a preoperative mean of $37.5 \pm 7.3 \mathrm{~mm} \mathrm{Hg}$ (range, 22-58) to $18.4 \pm 7.3 \mathrm{~mm} \mathrm{Hg}$ (range, $3-34)(P<0.01)$ at 6 months, $22.9 \pm 11.1 \mathrm{~mm} \mathrm{Hg}$ (range, $11-35)$ at 12 months $(P<0.01)$ and $21.8 \pm 9.3 \mathrm{~mm} \mathrm{Hg}$ (range, 19-39) at 24 months $(P<0.01)$. The mean IOP at the last follow-up examination was $22.9 \pm 11.1 \mathrm{~mm} \mathrm{Hg}$ (range, $0-58$ ), which was significantly lower than preoperative values.

The number of glaucoma medications significantly decreased from a preoperative mean of 2.3 (range, 1-4) to 1.4 (range, 1-3) at 6 months after AVI. The number of glaucoma medications was not significantly different from preoperative values at 12,24 months, and the last follow-up examination (mean 1.8; range, $0-4 ; P=0.17$, $P=0.86, P=0.41$ by Wilcoxon signed rank test).

After 12 months, 19 eyes (63.3\%) met the criteria of qualified success, and 4 eyes (13.3\%) showed complete success. Success rates declined over time, and at the last follow-up examination, 17 eyes (50.0\%) showed qualified success and 6 eyes (17.6\%) showed complete success (Table 2).

The cumulative probabilities of qualified success at 6 , 12, and 24 months after AVI, according to life table analysis (Kaplan-Meier plot), were 89.0, 68.6, and 45.7\%, 
respectively. The median time of survival was $19.6 \pm 0.9$ months (Figure 1).

Univariate analysis of risk factors for failure, in terms of qualified success, was compared between subgroups. There was no significant difference in success rates at the last follow-up examination between subgroups of different diagnosis $(P=0.06 \sim 0.83)$, age $(P=0.90)$, presence of previous glaucoma surgery $(P=0.79$; Table 3$)$, or combined surgery $(P=0.70)$.

Postoperative complications occurred in six eyes $(17.6 \%)$ after a mean interval of $6.3 \pm 5.6$ months (range, 0-17; Table 4). The most common complication was shallow anterior chamber, occurring in three eyes (8.8\%). Hyphema occurred in two eyes (5.9\%) with neovascular glaucoma, both of which spontaneously resolved. The

Table 2 Success rates after Ahmed valve implantation

\begin{tabular}{|c|c|c|c|}
\hline Period & $\begin{array}{c}\text { Number of } \\
\text { eyes }\end{array}$ & $\begin{array}{l}\text { Qualified } \\
\text { success }^{\mathrm{a}}\end{array}$ & $\begin{array}{l}\text { Complete } \\
\text { success }^{\mathrm{b}}\end{array}$ \\
\hline \multicolumn{4}{|l|}{ Postoperative } \\
\hline 6 months & 34 & $25(73.5 \%)$ & $8(23.5 \%)$ \\
\hline 12 months & 30 & $19(63.3 \%)$ & $4(13.3 \%)$ \\
\hline Last follow-up ${ }^{c}$ & 34 & $17(50.0 \%)$ & $6(17.6 \%)$ \\
\hline
\end{tabular}

${ }^{\text {a } Q u a l i f i e d ~ s u c c e s s: ~ I O P ~} \leqslant 21 \mathrm{~mm} \mathrm{Hg}$ regardless of the number of glaucoma medications.

${ }^{\mathrm{b} C}$ Complete success: IOP $\leqslant 21 \mathrm{~mm} \mathrm{Hg}$ without glaucoma medication.

'Last follow-up period was $29.1 \pm 16.2$ months (range, 6-63). most threatening complication developed in one eye (2.9\%) of congenital glaucoma. Hypotony, shallowing of the anterior chamber, and choroidal detachment developed 3 months after AVI that was refractory to conservative management, followed by retinal detachment 9 months after surgery. Tube exposure was found in one eye (2.9\%) 4 months after surgery and was surgically repaired with scleral graft and amniotic membrane transplantation. Tube occlusion by iris tissue segments developed in one eye $(2.9 \%)$ together with shallow anterior chamber at 15 months after AVI. Surgical revision with anterior chamber reformation was successfully performed.

Of the five patients (17.2\%) who underwent bilateral AVI, male to female ratio was $1: 4$, and the mean time interval between the operations of fellow eyes was $6.0 \pm 12.0$ months (range, $0-27$ ). The preoperative mean IOP was not significantly different between fellow eyes ( $P=0.35$ by paired $t$-test). The mean follow-up time (35.4 \pm 17.1 months; range, 12-63) was not different between fellow eyes ( $P=0.28$ by paired $t$-test). At 12 months after AVI, bilateral valve survival was found in two patients with congenital glaucoma and pseudophakic glaucoma (40\%). Unilateral failure occurred in two patients (20\%) with congenital glaucoma (3 months) and Axenfeld-Rieger anomaly (12 months). Bilateral failure occurred in one patient (20\%) with aphakic glaucoma (1 month). No additional failure

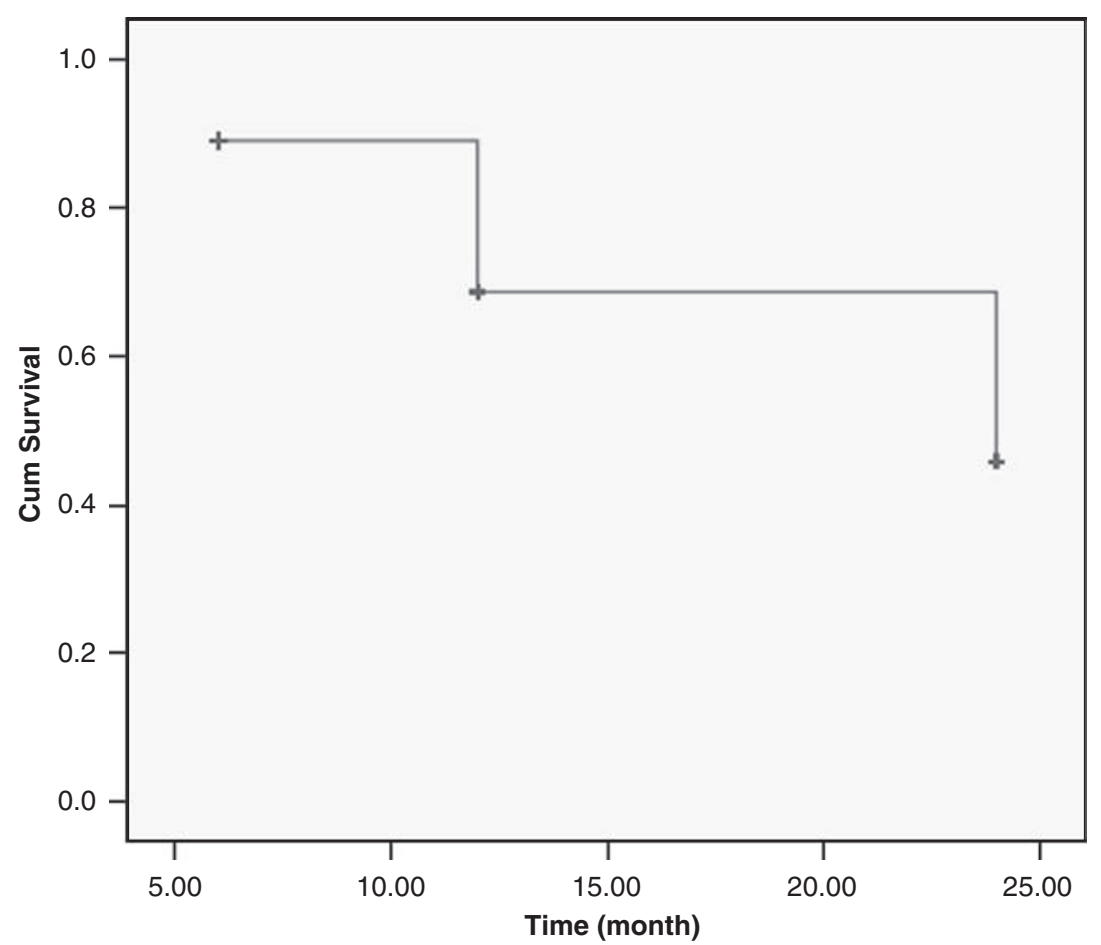

Figure 1 The cumulative probabilities of qualified success at 6, 12, and 24 months after Ahmed valve implantation, according to life table analysis (Kaplan-Meier plot), were 89.0, 68.6, and 45.7\%, respectively. The median time of valve survival was $19.6 \pm 0.9$ months. 
Table 3 Comparison of success rates at last follow-up after Ahmed valve implantation between subgroups of different diagnosis, age group, and previous glaucoma surgery

\begin{tabular}{|c|c|c|c|}
\hline Glaucoma diagnosis & Eyes $(N)$ & Success $^{\mathrm{a}}$ & Follow-up (mo) \\
\hline Congenital glaucoma & 12 & $9(75.0 \%)$ & $40.6 \pm 17.0$ \\
\hline Aphakic/pseudophakic glaucoma & 11 & $7(63.6 \%)$ & $20.0 \pm 9.5$ \\
\hline Glaucoma with ocular anomalies ${ }^{\mathrm{b}}$ & 5 & $1(20.0 \%)$ & $25.2 \pm 13.5$ \\
\hline Neovascular glaucoma & 4 & $1(25.0 \%)$ & $24.5 \pm 13.9$ \\
\hline Glaucoma with systemic disease $^{c}$ & 1 & $0(0 \%)$ & $13.0 \pm 0$ \\
\hline Glaucoma associated with cicatricial ROP & 1 & $1(100 \%)$ & $47.0 \pm 0$ \\
\hline$P$-value & & $0.06 \sim 0.83^{\mathrm{d}}$ & $0.05^{\mathrm{e}}$ \\
\hline Age at operation & $\begin{array}{c}\text { Younger group } \\
(0-5 \text { years }) \\
\%(N=20)\end{array}$ & $\begin{array}{c}\text { Older group } \\
(6 \sim 18 \text { years }) \\
\%(N=14)\end{array}$ & P-value \\
\hline Success ${ }^{\mathrm{a}}$ & $55.0 \%(11)$ & $57.1 \%(8)$ & $0.90^{\mathrm{d}}$ \\
\hline Follow-up (mo) & $30.0 \pm 16.0$ & $27.9 \pm 17.0$ & $0.67^{\mathrm{f}}$ \\
\hline Previous glaucoma surgery & $\begin{array}{l}\text { Initial AVI } \\
\%(N=19)\end{array}$ & $\begin{array}{c}\text { Previous glaucoma surgery } \\
\qquad \%(\mathrm{~N}=15)\end{array}$ & P-value \\
\hline Success $^{\mathrm{a}}$ & $57.9 \%(11)$ & $53.3 \%(8)$ & $0.79^{\mathrm{d}}$ \\
\hline Follow-up (mo) & $23.9 \pm 13.0$ & $35.7 \pm 17.8$ & $0.06^{\mathrm{f}}$ \\
\hline
\end{tabular}

Abbreviations: AVI, Ahmed valve implantation; mo, months; IOP, intraocular pressure; ROP, retinopathy or prematurity.

aQualified success: IOP $\leqslant 21 \mathrm{~mm} \mathrm{Hg}$ regardless of the number of glaucoma medications.

b Glaucoma associated with aniridia, Axenfeld-Rieger anomaly, or microphthalmia.

cGlaucoma associated with Down syndrome.

${ }^{\mathrm{d}}$ Univariate analysis of success rates between different subgroups by Pearson's $\chi^{2}$-test.

'The follow-up period was not significantly different between subgroups by Kruskal-Wallis test.

${ }^{\mathrm{f}}$ The follow-up period was not significantly different between subgroups by Mann-Whitney $U$ test.

Table 4 Postoperative complications after Ahmed valve implantation

\begin{tabular}{|c|c|c|c|}
\hline Complication & Number of eyes $N(\%)$ & Postoperative Period (months) & Treatment \\
\hline Shallow anterior chamber ${ }^{a}$ & $3(8.8 \%)$ & $0,0,15$ & Chamber reformation \\
\hline Hypotony (IOP $<5 \mathrm{~mm} \mathrm{Hg}$ ) & $1(2.9 \%)$ & 3 & Observation $^{\mathrm{b}}$ \\
\hline Hyphema & $2(5.9 \%)$ & 0,0 & Spontaneous resolution \\
\hline Tube exposure & $1(2.9 \%)$ & 4 & Scleral graft \\
\hline Tube occlusion & $1(2.9 \%)$ & 15 & Surgical revision $^{c}$ \\
\hline Choroidal detachment & $1(2.9 \%)$ & 3 & Observation $^{\mathrm{b}}$ \\
\hline Retinal detachment & $1(2.9 \%)$ & 9 & Observation $^{\mathrm{b}}$ \\
\hline No complications & $28(82.4 \%)$ & & \\
\hline
\end{tabular}

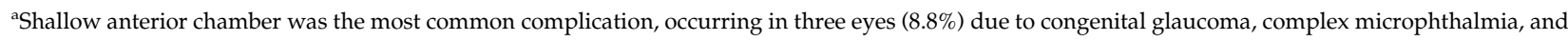
neovascular glaucoma in insulin dependent diabetes mellitus.

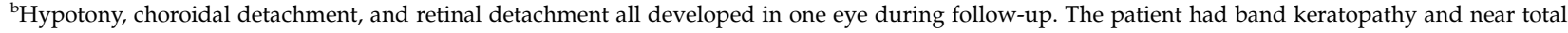
corneal opacity prior to Ahmed valve implantation. No further intervention was performed as the parents declined additional procedures.

${ }^{\mathrm{c}}$ Tube occlusion was partial by iris tissue segments plugging the tube orifice, following a flat anterior chamber. The occlusive tissues were surgically removed at the time of anterior chamber reformation.

occurred after 12 months and no significant complications were found in all eyes until the last follow-up examination.

Of the 11 eyes (32.4\%) that failed after AVI, 5 eyes (45.5\%) underwent second AVI in the superonasal quadrant. The mean number of previous glaucoma surgeries before Ahmed implant was 3 (range, 1-5). The time interval between the successive implantations was $18.8 \pm 7.9$ months (range, 13-32). The mean follow-up time after the second AVI was $26.6 \pm 12.7$ months (range,
$12-47)$. Four eyes $(80 \%)$ showed qualified $(n=2 ; 40 \%)$ or complete $(n=2 ; 40 \%)$ success at the last follow-up examination without any significant complications.

\section{Discussion}

Success rates after AVI in refractory paediatric glaucoma are variable in previous reports, but all show a relative decline over time. ${ }^{9,36-38}$ The cumulative probabilities of success rates reported at 1, 2, 3, and 4 years after AVI is 
70-93, 50-86, 52-71, and 42-45\%, respectively. ${ }^{29,30,33,39,40}$ Other implants, such as Molteno or Baerveldt implants, have shown similar success rates and valve survival. ${ }^{23-25,37}$ In this study, the cumulative probability of qualified success at 6, 12, and 24 months after AVI in patients younger than 18-year-old were 89.0, 68.6, 45.7\%, respectively. This falls to the lower end of success rates demonstrating limited success. ${ }^{29,30,33,39,40}$

The different type of valve used may be one reason of limited success. In this study, Ahmed valves designed for children (S-3) were used for patients under 12 years, instead of the adult model (S-2). Although the tube properties are equal, the S-3 model is slightly smaller in valve width and length and the surface area is half the size of the adult model. A smaller model may be preferred in paediatric patients to prevent tube-corneal contact, which tends to occur in eyes of very young patients with low scleral rigidity, perhaps because of anterior rotation of the tube due to lower holding power of sclera around the tube and postoperative depression of sclera by the volume of the plate. ${ }^{41}$ However, the reduced surface area and width of the valve may be related to decreased filtration, resulting in limited success as in this study. Hence, an ultrasonic biometry of globe size may be useful in deciding the size of the implant. However, in our study, qualified success rates of the S-3 model were not different with the S-2 model ( $P=0.59$ by Fisher's exact test) and was not related to patients age $(P=0.80$ by Mann-Whitney $U$ test). As globe size or corneal diameter was not included in this study, it remains to be elucidated whether the paediatric model (S-3) is more useful in patients with a smaller globe. This promotes the use of ultrasonic biometry to select candidates for the S-3 model.

The lack of postoperative manipulations may be another reason of limited success. In our study, postoperative needling was barely possible due to general conditions and poor cooperation of young patients. This may be why postoperative needling, although effective in adults, is seldom described in studies of refractory paediatric glaucoma. ${ }^{32,42-44}$

Risk factors for failure after AVI were not evident in our study. Qualified success rates of AVI at last follow-up were not significantly different between subgroups of specific glaucoma diagnosis, age at the time of surgery, presence of previous glaucoma surgery, or combined surgical procedures. However, studies are controversial concerning risk factors for failure after AVI. One of the most common risk factors is glaucoma diagnosis.

Djodeyre et $a l^{39}$ noted that congenital glaucoma, number of previous glaucoma surgeries, and surgical experience were significantly related to valve survival. Coleman et $a l^{29}$ also suggested a higher risk of failure in eyes with congenital glaucoma than in eyes with other diagnoses in the paediatric population. Nevertheless, others have reported high success rates $(92.9 \%)$ in congenital glaucoma patients. ${ }^{40}$ Our study also demonstrated a high success rate $(75.0 \%)$ in congenital glaucoma patients after a mean follow up of $40.6 \pm 17.0$ months, which was not significantly different between other diagnoses.

One eye underwent combined PKP with AVI, and qualified success was maintained up to 4 years after surgery. Coleman et al ${ }^{45}$ presented figures of cumulative probability of success as $76 \%$ at 12 months and $52 \%$ at 20 months in eyes having AVI with prior or concurrent PKP in adult glaucomas. This was comparable to success rates after simple glaucoma valve surgeries, which suggests that combined PKP does not influence the survival of AVI in children and adults.

The advantage of AVI over filtration surgery or other non-valved implants can be explained as follows. The Ahmed valve consists of a flexible drainage tube and an equatorial plate, which are made up of materials (polymethylmethacrylate, polypropylene, silicone rubber) relatively resistant to fibroblast attachment. The internal diameter of the tube does not narrow, letting floating matter in the anterior chamber pass through the tube without occlusion. The unidirectional valve that opens at pressures over $8 \mathrm{~mm} \mathrm{Hg}$ can prevent immediate postoperative hypotony or IOP spikes. ${ }^{46}$ The equatorial filtration blebs are also beneficial in maintaining the initial bleb size and function, through their lower propensity toward contraction of the fibrous capsule compared to the limbal blebs of trabeculectomy. ${ }^{24,47}$ Antimetabolites such as mitomycin C or 5-fluorouracil can be applied to prevent excessive scar formation; however, some authors report a higher risk of complications in the paediatric population compared to adults. ${ }^{48-50}$

Postoperative complications after AVI include hypotony (IOP $\leqslant 5 \mathrm{~mm} \mathrm{Hg})(11-42 \%)$, shallow anterior chamber (15 26\%), tube malposition (5 26\%), tubecorneal touch $(3 \sim 8 \%)$, tube occlusion (14\%), tube exposure $(6 \sim 12 \%)$, and other rare complications such as tenon encapsulated cyst $(1 \sim 7 \%)$, postoperative cataract $(0 \sim 2 \%)$, strabismus $(0 \sim 3 \%)$, retinal or choroidal detachment $(1 \sim 18 \%)$, endophthalmitis $(1 \sim 5 \%)$, wound leak $(3 \%)$, plate migration ( $2 \%)$, inflammation, hyphema, delayed retrobulbar haemorrhage. ${ }^{28-30,33,39,51,52}$ In our study, overall rates of complications was lower than previously reported. Shallow anterior chamber $(8.8 \%)$ was most commonly encountered, but found in a lower rate compared to other studies. Most of the complications occurred within 4 months, whereas one eye developed partial tube occlusion with iris tissue plugging due to flattening of the anterior chamber at 15 months after AVI. Trigler $e t a l^{53}$ histologically documented one of the causes of tube occlusion as the presence of fibrovascular 
ingrowth in their Ahmed glaucoma valve, and the mean time to failure and explantation was 23 months after implantation (range, 6-65 months). However, in our case, tube occlusion with iris tissues plugging the orifice was surgically managed without causing valve failure.

One devastating complication occurred in a patient with congenital glaucoma. Hypotony, flat anterior chamber, and choroidal detachment developed 3 months after surgery, followed by retinal detachment. In this case, band keratopathy was present prior to AVI, and AVI had been performed for pain and IOP control. Further intervention was not possible as the parents declined additional procedures. Retinal detachment is rarely reported after AVI, but the rates in our study (2.9\%) were similar to those reported with other implants. ${ }^{23,26,54}$ Retinal detachment following choroidal detachment is reported after severe ocular inflammation, ${ }^{55}$ but in our case, there was no sign of severe inflammation. A silent retinal tear or shallow retinal detachment may have been present much earlier in the development of hypotony, masked by choroidal detachment. $^{56,57}$

Treatment is required after certain complications. Two eyes that failed shortly after surgery showed corneal decompensation requiring PKP. Iris tissues causing tube occlusion along with flat anterior chamber were surgically removed at the time of anterior chamber reformation. Tube exposure was managed with scleral patch graft and amniotic membrane graft. Hypotony and choroidal detachment was observed without management due to near total corneal opacity and poor compliance. Most cases of postoperative choroidal detachment resolve spontaneously, usually associated with rapid normalization of IOP and reduction of inflammation. ${ }^{56}$ Surgical management involving vortex vein decompression or sclerotomy can be effective in some patients. ${ }^{58}$ In our case, hypotony was sustained, progressing unto retinal detachment, suggesting the possibility of a preexisting retinal detachment not found until later progression. No further interventions were taken according to the parents' will. Other nondevastating complications spontaneously resolved or were asymptomatic (Table 4).

The presence of a hypertensive phase, defined as IOP $>21 \mathrm{~mm} \mathrm{Hg}$ during the first 3 months after surgery, was seen in 20 eyes (59\%). This is comparable to previous studies, which showed a hypertensive phase in $25 \sim 82 \%$ of patients after AVI in adults. ${ }^{30,59}$ The incidence of a hypertensive phase is known to be more frequent after AVI compared to non-valve implantation. ${ }^{59}$ NouriMahdavi and Caprioli ${ }^{59}$ found a hypertensive phase in $56 \%$ of adults after AVI, but resolution of the hypertensive phase was observed in only $28 \%$. However, in paediatric glaucoma, Chen et $a l^{30}$ found $25 \sim 40.4 \%$ having a hypertensive phase, demonstrating a lower incidence in children compared to adults.

The resolution of the hypertensive phase, defined as an IOP $\leqslant 21 \mathrm{~mm} \mathrm{Hg}$ and IOP reduction of $3 \mathrm{~mm} \mathrm{Hg}$ with the same or fewer number of glaucoma medications, was found in 15 out of 20 eyes (75\%). The resolution rate was much higher than in adults $(28 \%)$, suggesting better control of transient IOP elevation after AVI in children. ${ }^{59}$

Additional AVI after failure of the primary implant was found to be effective in our study. Out of 11 failed eyes, 5 (45.5\%) underwent additional AVI without removal of the primary implant. This was carried out under the notion that removal of the primary implant was traumatic, and the failed valve may still be partially functioning. Four eyes (80\%) survived at last follow-up (mean, 26.6 \pm 12.7 months), whereas long-term valve survival remains to be elucidated.

Despite the limitations of its retrospective nature and small number of cases in this study, AVI seems to be effective in refractory paediatric glaucoma. The paediatric model (S-3) showed comparable but limited success rates. Selective candidates for a smaller valve remain to be elucidated. Success rates decline over time, and considering the need for longer valve survival in the paediatric population, efforts to develop alternative medications or surgical procedures are promoted for longterm survival. Additional AVI may be considered as a treatment option after failure of the primary implantation.

\section{References}

1 Beck AD. Diagnosis and management of pediatric glaucoma. Ophthalmol Clin North Am 2001; 14: 501-512.

2 Turach ME, Aktan G, Idil A. Medical and surgical aspects of congenital glaucoma. Acta Ophthalmol Scand 1995; 73: 261-263.

3 Maris Jr PJ, Mandal AK, Netland PA. Medical therapy of pediatric glaucoma and glaucoma in pregnancy. Ophthalmol Clin North Am 2005; 18: 461-468.

4 Zimmerman TJ, Kooner KS, Morgan KS. Safety and efficacy of timolol in pediatric glaucoma. Surv Ophthalmol 1983; 28(Suppl): 262-264.

5 Portellos M, Buckley EG, Freedman SF. Topical versus oral carbonic anhydrase inhibitor therapy for pediatric glaucoma. J AAPOS 1998; 2: 43-47.

6 Enyedi LB, Freedman SF. Latanoprost for the treatment of pediatric glaucoma. Surv Ophthalmol 2002; 47(Suppl 1): 129-132.

7 Sabri K, Levin AV. The additive effect of topical dorzolamide and systemic acetazolamide in pediatric glaucoma. J AAPOS 2006; 10: 464-468.

8 deLuise VP, Anderson DR. Primary infantile glaucoma (congenital glaucoma). Surv Ophthalmol 1983; 28: 1-19.

9 Meyer G, Schwenn O, Pfeiffer N, Grehn F. Trabeculotomy in congenital glaucoma. Graefes Arch Clin Exp Ophthalmol 2000; 238: 207-213.

10 Yalvac IS, Satana B, Suveren A, Eksioglu U, Duman S. Success of trabeculotomy in patients with congenital glaucoma operated on within 3 months of birth. Eye 2007; 21: $459-464$. 
11 McPherson Jr SD, Berry DP. Goniotomy vs external trabeculotomy for developmental glaucoma. Am J Ophthalmol 1983; 95: 427-431.

12 Tamcelik N, Ozkiris A. Long-term results of viscotrabeculotomy in congenital glaucoma: comparison to classical trabeculotomy. Br J Ophthalmol 2008; 92: 36-39.

13 Noureddin BN, El-Haibi CP, Cheikha A, Bashshur ZF. Viscocanalostomy versus trabeculotomy ab externo in primary congenital glaucoma: 1-year follow-up of a prospective controlled pilot study. Br J Ophthalmol 2006; 90: 1281-1285.

14 Elder MJ. Combined trabeculotomy-trabeculectomy compared with primary trabeculectomy for congenital glaucoma. Br J Ophthalmol 1994; 78: 745-748.

15 Beck AD, Wilson WR, Lynch MG, Lynn MJ, Noe R. Trabeculectomy with adjunctive mitomycin $\mathrm{C}$ in pediatric glaucoma. Am J Ophthalmol 1998; 126: 648-657.

16 O'Connor G. Combined trabeculotomy-trabeculectomy for congenital glaucoma. Br J Ophthalmol 1994; 78: 735.

17 al-Hazmi A, Zwaan J, Awad A, al-Mesfer S, Mullaney PB, Wheeler DT. Effectiveness and complications of mitomycin $\mathrm{C}$ use during pediatric glaucoma surgery. Ophthalmology 1998; 105: 1915-1920.

18 Sidoti PA, Belmonte SJ, Liebmann JM, Ritch R. Trabeculectomy with mitomycin-C in the treatment of pediatric glaucomas. Ophthalmology 2000; 107: 422-429.

19 Dascotte JC, Asseman R, François P, Houliez T, Huron JC, Castier $\mathrm{P}$ et al. Surgical treatment of congenital glaucoma. Long-term results. J Fr Ophtalmol 1991; 14: 229-233.

20 al Faran MF, Tomey KF, al Mutlaq FA. Cyclocryotherapy in selected cases of congenital glaucoma. Ophthalmic Surg 1990; 21: 794-798.

21 Phelan MJ, Higginbotham EJ. Contact transscleral Nd: YAG laser cyclophotocoagulation for the treatment of refractory pediatric glaucoma. Ophthalmic Surg Lasers 1995; 26: 401-403.

22 Alvarado JA. Endocyclophotocoagulation for pediatric glaucoma: a tale of two cities. J AAPOS 2007; 11: 10-11.

23 Netland PA, Walton DS. Glaucoma drainage implants in pediatric patients. Ophthalmic Surg 1993; 24: 723-729.

24 Ishida K, Mandal AK, Netland PA. Glaucoma drainage implants in pediatric patients. Ophthalmol Clin North Am 2005; 18: 431-442.

25 Molteno A. Children with advanced glaucoma treated by draining implants. S Afr Arch Ophthalmol 1973; 1: 55-61.

26 Budenz DL, Gedde SJ, Brandt JD, Kira D, Feuer W, Larson E. Baerveldt glaucoma implant in the management of refractory childhood glaucomas. Ophthalmology 2004; 111: 2204-2210.

27 van Overdam KA, de Faber JT, Lemij HG, de Waard PW. Baerveldt glaucoma implant in paediatric patients. $\mathrm{Br} J$ Ophthalmol 2006; 90: 328-332.

28 Hamush NG, Coleman AL, Wilson MR. Ahmed glaucoma valve implant for management of glaucoma in Sturge-Weber syndrome. Am J Ophthalmol 1999; 128: 758-760.

29 Coleman AL, Smyth RJ, Wilson MR, Tam M. Initial clinical experience with the Ahmed Glaucoma Valve implant in pediatric patients. Arch Ophthalmol 1997; 115: 186-191.

30 Chen TC, Bhatia LS, Walton DS. Ahmed valve surgery for refractory pediatric glaucoma: a report of 52 eyes. J Pediatr Ophthalmol Strabismus 2005; 42: 274-283.

31 O'Malley Schotthoefer E, Yanovitch TL, Freedman SF. Aqueous drainage device surgery in refractory pediatric glaucoma: II. Ocular motility consequence. J AAPOS 2008 ; 12: $40-45$.

32 Kirwan C, O'Keefe M, Lanigan B, Mahmood U. Ahmed valve drainage implant surgery in the management of paediatric aphakic glaucoma. Br J Ophthalmol 2005; 89: 855-858.

33 Morad Y, Donaldson CE, Kim YM, Abdolell M, Levin AV. The Ahmed drainage implant in the treatment of pediatric glaucoma. Am J Ophthalmol 2003; 135: 821-829.

34 Kafkala C, Hynes A, Choi J, Topalkara A, Foster CS. Ahmed valve implantation for uncontrolled pediatric uveitic glaucoma. J AAPOS 2005; 9: 336-340.

35 Kee C. Prevention of early postoperative hypotony by partial ligation of silicone tube in Ahmed glaucoma valve implantation. J Glaucoma 2001; 10: 466-469.

36 Wagle NS, Freedman SF, Buckley EG, Davis JS, Biglan AW. Long-term outcome of cyclocryotherapy for refractory pediatric glaucoma. Ophthalmology 1998; 105: 1921-1926.

37 Autrata R, Helmanova I, Oslejskova H, Vondracek P, Rehurek J. Glaucoma drainage implants in the treatment of refractory glaucoma in pediatric patients. Eur J Ophthalmol 2007; 17: 928-937.

38 Souza C, Tran DH, Loman J, Law SK, Coleman AL, Caprioli J. Long-term outcomes of Ahmed glaucoma valve implantation in refractory glaucomas. Am J Ophthalmol 2007; 144: 893-900.

39 Djodeyre MR, Peralta Calvo J, Abelairas Gomez J. Clinical evaluation and risk factors of time to failure of Ahmed glaucoma valve implant in pediatric patients. Ophthalmology 2001; 108: 614-620.

40 Englert JA, Freedman SF, Cox TA. The Ahmed valve in refractory pediatric glaucoma. Am J Ophthalmol 1999; 127: 34-42.

41 Das JC, Chaudhuri Z, Sharma P, Bhomaj S. The Ahmed glaucoma valve in refractory glaucoma: experiences in Indian eyes. Eye 2005; 19: 183-190.

42 Broadway DC, Bloom PA, Bunce C, Thiagarajan M, Khaw PT. Needle revision of failing and failed trabeculectomy blebs with adjunctive 5-fluorouracil: survival analysis. Ophthalmology 2004; 111: 665-673.

43 Perucho-Martinez S, Gutierrez-Diaz E, Montero-Rodriguez M, Mencia-Gutierrez E, Lago-Llinas MD. Needle revision of late failing filtering blebs after glaucoma surgery. Arch Soc Esp Oftalmol 2006; 81: 517-522.

44 Hawkins AS, Flanagan JK, Brown SV. Predictors for success of needle revision of failing filtration blebs. Ophthalmology 2002; 109: 781-785.

45 Coleman AL, Mondino BJ, Wilson MR, Casey R. Clinical experience with the Ahmed glaucoma valve implant in eyes with prior or concurrent penetrating keratoplasties. Am J Ophthalmol 1997; 123: 54-61.

46 Frank R. Valve may boost success rate. Ophthalmology Times 1996; 21: 29-30.

47 Atreides SP, Skuta GL, Reynolds AC. Wound healing modulation in glaucoma filtering surgery. Int Ophthalmol Clin 2004; 44: 61-106.

48 Freedman SF, McCormick K, Cox TA. Mitomycin $\mathrm{C}$-augumented trabeculectomy with postoperative wound modulation in pediatric glaucoma. J AAPOS 1999; 3: 117-124.

49 Snir M, Lusky M, Shalev B, Gaton D, Weinberger D. Mitomycin $\mathrm{C}$ and 5-fluorouracil antimetabolite therapy for pediatric glaucoma filtration surgery. Ophthalmic Surg Lasers 2000; 31: 31-37. 
50 Rodrigues AM, Junior AP, Montezano FT, de Arruda Melo PA, Prata Jr J. Comparison between results of trabeculectomy in primary congenital glaucoma with and without the use of mitomycin C. J Glaucoma 2004; 13: 228-232.

51 Eibschitz-Tsimhoni M, Schertzer RM, Musch DC, Moroi SE. Incidence and management of encapsulated cysts following Ahmed glaucoma valve insertion. J Glaucoma 2005; 14: 276-279.

52 Chan CH, Lai JS, Shen SY. Delayed retrobulbar haemorrhage after Ahmed glaucoma implant: a case report. Eye 2006; 20: 494-495.

53 Trigler L, Proia AD, Freedman SF. Fibrovascular ingrowth as a cause of Ahmed glaucoma valve failure in children. Am J Ophthalmol 2006; 141: 388-389.

54 Munoz M, Tomey KF, Traverso C, Day SH, Senft SH. Clinical experience with the Molteno implant in advanced infantile glaucoma. J Pediatr Ophthalmol Strabismus 1991; 28 : 68-72.
55 Jarrett WH. Rhematogenous retinal detachment complicated by severe intraocular inflammation, hypotony, and choroidal detachment. Trans Am Ophthalmol Soc 1981; 79: 664-683.

56 Law SK, Kalenak JW, Connor Jr TB, Pulido JS, Han DP, Mieler WF. Retinal complications after aqueous shunt surgical procedures for glaucoma. Arch Ophthalmol 1996; 114: $1473-1480$.

57 De Smedt S, Sullivan P. Massive choroidal detachment masking overlying primary rhegmatogenous retinal detachment: a case series. Bull Soc Belge Ophtalmol 2001; 282: 51-55.

58 Obuchowska I, Mariak Z. Choroidal detachment - pathogenesis, etiology and clinical features. Klin Oczna 2005; 107: 529-532.

59 Nouri-Mahdavi K, Caprioli J. Evaluation of the hypertensive phase after insertion of the Ahmed glaucoma valve. Am J Ophthalmol 2003; 136: 1001-1008. 